\title{
From the Communism of Capital to Capital for the Commons: Towards an Open Co-operativism
}

\author{
Michel Bauwens* and Vasilis Kostakis** \\ *P2P Foundation; FLOK Society, Quito, Ecuador; michel@p2pfoundation.net \\ ${ }^{* *} P 2 P$ Foundation; Tallinn University of Technology, Tallinn, Estonia; P2P Lab, Ioannina, \\ Greece; vasileios.kostakis@ttu.ee
}

\begin{abstract}
Two prominent social progressive movements are faced with a few contradictions and a paradox. On the one side, we have a re-emergence of the co-operative movement and worker-owned enterprises which suffer from certain structural weaknesses. On the other, we have an emergent field of open and Commons-oriented peer production initiatives which create common pools of knowledge for the whole of humanity, but are dominated by start-ups and large multinational enterprises using the same Commons. Thus we have a paradox: the more communist the sharing license used in the peer production of free software or open hardware, the more capitalist the practice. To tackle this paradox and the aforementioned contradictions, we tentatively suggest a new convergence that would combine both Commons-oriented open peer production models with common ownership and governance models, such as those of the co-operatives and the solidarity economic models.
\end{abstract}

Keywords: Ethical Economy, Commons, Free Software, Business Models, Legal, Peer Production, Peer Property, Peer Production License, Co-operatives

Acknowledgement: Precursor of this paper were two entries by Michel Bauwens in the P2P Foundation wiki (http://tinyurl.com/p8syh49 and http://tinyurl.com/nbzqvwf). Vasilis Kostakis acknowledges support by the "Challenges to State Modernization in 21st Century Europe" Estonian Institutional Grant [IUT 19-13].

A few contradictions can be observed in the modern progressive social movements.

On the one hand, we are witnessing a re-emergence of the co-operative movement and worker-owned enterprises (see Restakis 2010). However, they arguably suffer from certain structural weaknesses. The co-operative entities work for their own members and, thus, are sometimes reluctant to accept new co-operators that would share existing profits and benefits. In addition, they are practitioners of the same proprietary knowledge and artificial scarcities tactics as their capitalist counterparts. That is, they might adopt monopoly pricing mechanisms such as those enabled by exclusive intellectual property rights. Moreover, even though they are internally democratic, they often participate in the same dynamics of capitalist competition which contradicts and, in the long run, may undermine their own cooperative values.

On the other hand, we have an emergent wave of open and Commons-oriented peer production efforts in fields such as free software, open design and open hardware, which do create common pools of knowledge for the whole of humanity. Nevertheless, at the same time they are dominated by both start-ups and large multinational enterprises exploiting and capitalizing on the same Commons. In other words, peer production functions within the cycle of accumulation of capital but also within the new cycle of the creation and circulation of the Commons (Bauwens 2013). Today the egalitarian potential of the Commons-based peer production seems promising but also the possibility for a parody should not be negligible (Kostakis and Stavroulakis 2013).

Therefore, we need a new convergence or synthesis, an "open co-operativism" if you like, that would combine Commons-oriented open peer production models with common ownership and governance models such as those of the co-operatives and the solidarity economic models. What follows is a more detailed argument on how such a transition could 
be achieved.

\section{Paradox}

Today we have a paradox: the more "communist" the sharing license we use (that is, no restrictions on sharing) in the peer production of free software or open hardware, the more capitalist the practice (that is, multinationals can use it for free). Take for example the Linux Commons which has become a corporate Commons as well, enriching big, for-profit corporations such as IBM (see Kostakis and Bauwens 2014). It is obvious that this works in a certain way and seems acceptable to most free software developers. But is this the optimal way?

Indeed, the General Public License and its variants allow anyone to use and modify the software code (or design), as long as the changes are integrated back in the common pool under the same conditions for further users. Our argument does not focus on the legal, contractual basis of the GPL and similar licenses, but on the social logic that they enable, which is: it allows anybody to contribute, and it allows anybody to use. In fact this relational dynamic is technically a form of "communism": from each according to his/her abilities, to each according to his/her needs. This paradoxically allows multinational corporations to use the free software code for profit maximization and capital accumulation. The result is that we do have an accumulation and circulation of information Commons, based on open input, participatory processes, and Commons-oriented output; but it is subsumed to capital accumulation. Therefore, currently it is not possible, or at least easy, to have social reproduction (that is, to create sustainable livelihoods) within the sphere of the Commons. The majority of the contributors participate on a voluntary basis, and those, who have an income, make a living either through wage-labor or alliances with capital-driven entities.

Hence the free software and culture movements, however important they might be as new social forces and expression of new social demands, are also, in essence, "liberal" in the tradition of the political ideology of liberalism. This is not only acknowledged by key figures such as Stallman, but also by anthropological studies like those of Coleman and others (2004; Coleman and Golub 2008; Coleman and Hill 2004). We could say they are liberalcommunist and communist-liberal movements, which create a "communism of capital".

The question is whether Commons-based peer production, that is, a new proto-mode of production, can generate the institutional capacity and alliances needed to break the political power of the old order. Ultimately the potential of the new mode is the same as those of the previous proto-modes of production - to emancipate itself from its dependency on the old decaying mode, so as to become self-sustaining and thus replace the accumulation of capital with the circulation of the Commons. An independent circulation of the Commons, where the common use-value would directly contribute to the further strengthening of the Commons and of the commoners' own sustainability, without dependence on capital. How could this be achieved?

\section{Alternative}

Is there an alternative? We believe that there is: to replace the non-reciprocal licenses, that is those which do not demand a direct reciprocity from its users, with one based on reciprocity. You may consider it as a switch from "communist" to "socialist licenses" or a swift from non-reciprocal licenses to a Commons-based reciprocal license (for a discussion of reciprocity in relation to licensing see de Filippi and Vieira 2013). We argue that the Peer Production License (PPL), designed and proposed by Kleiner (2010), exemplifies this line of argument. PPL should not to be confused with the Creative Commons (CC) non commercial (NC) license, as its logic is different. The CC-NC offers protection to individuals reluctant to share, as they do not wish a commercialization of their work that would not reward them for their labor. Thus the CC-NC license stops the further economic development based on this open and shared knowledge, and keeps it entirely in the not-for-profit sphere.

The logic of the PPL is to allow commercialization, but on the basis of a demand for reciprocity. It is designed to enable and empower a counter-hegemonic reciprocal economy 
that combines Commons that is open to all that contribute, while charging a license fee for the for-profit companies who would like to use it without contributing. Not that much changes for the multinationals in practice; they can still use the code if they contribute, as IBM does with Linux. However, those who do not contribute should pay a license fee - a practice they are used to. Its practical effect would be to somehow direct a stream of income from capital to the Commons, but its main effect would be ideological, or if you like, value-driven.

The entrepreneurial coalitions that are linked around a PPL-based Commons would be explicitly oriented towards their contributions to the Commons, and the alternative value system that it represents. From the point of view of the peer producers or commoners, a Commons-based reciprocal license, like PPL, would allow the contributory communities to create their own co-operative entities. In this new ecology, profit would be subsumed to the social goal of sustaining the Commons and the commoners. Even the participating for-profit companies would consciously contribute under a new logic. This proposal would link the Commons to an entrepreneurial coalition of ethical market entities (co-ops and other models) and keep the surplus value entirely within the sphere of commoners/co-operators, instead of leaking out to the multinationals.

In other words, through this convergence or rather combination of a Commons model for the abundant immaterial resources, and a reciprocity-based model for the "scarce" material resources, the issue of livelihoods and social reproduction could be solved. The surplus value would be kept inside the Commons sphere itself. It is the co-operatives that would, through their co-operative accumulation, fund the production of immaterial Commons, because they would pay and reward the peer producers associated with them.

In this way, peer production could move from a proto-mode of production, unable to perpetuate itself on its own outside capitalism, to an autonomous and real mode of production. It would create a counter-economy that could be the basis for reconstituting a "counter-hegemony" with a for-benefit circulation of value. This process, allied to "proCommons" social movements, could be the basis of the political and social transformation of the political economy. Hence we might move from a situation in which the communism of capital is dominant, to a situation in which we have a "capital for the Commons", increasingly insuring the self-reproduction of the peer production mode.

For the moment, the PPL is used experimentally by "Guerrilla Translation!" and is being discussed in various places, such as in some French open agricultural machining and design communities (for example, in the ShareLex initiative). Also the team of the P2P Lab in Greece is discussing the use of the PPL in the second version of its collaborative theatrical play platform named "Wikitheater". The "man with the spotted tie" is probably the first play written on a wiki through asynchronous and distributed collaborative processes (for a full account of the initiative see Kostakis and Drechsler 2013). The text was firstly published in 2012 under a modified CC license: everybody was free to perform the play and use its soundtrack music for non-profit purposes. In a case of a for-profit usage, the creative team of the P2P Lab would negotiate on a case-by-case basis. With a modified license which offered negotiated reciprocity, the authors and musicians have managed to accumulate a small capital, now used to support the creation of an international wikitheater platform and the translation of "the man with the spotted tie".

The new open co-operativism would be substantially different from the previous form. In the old one, internal economic democracy is accompanied by participation in market dynamics on behalf of the members, using capitalist competition. There is an unwillingness to share profits and benefits with outsiders, hence, no creation of the Commons. We argue that an independent Commons-oriented economy should be in need of a different model in which the co-operatives produce Commons and are statutorily oriented towards the creation of the common good. To realize their goals they should adopt multi-stakeholders forms of governance which would include workers, users-consumers, investors and the concerned communities.

As said, today we have a situation where open communities of peer producers are largely oriented towards the start-up model and are subsumed to profit maximization, while the cooperatives remain closed, use exclusive intellectual property licenses, and, thus, do not 
create a Commons. In the new model of open co-operativism, a merger should occur between the open peer production of Commons and the co-operative production of value. The new open co-operativism would: i) integrate externalities; ii) practice economic democracy; iii) produce Commons for the common good; iv) and socialize its knowledge. The circulation of the Commons would be combined with the process of co-operative accumulation, on behalf of the Commons and its contributors. In the beginning, the immaterial Commons field, following the logic of free contributions and universal use for everyone who needs it, would co-exist with a co-operative model for physical production, based on reciprocity. But as the co-operative model would be becoming more and more hyper-productive being able to create sustainable abundance in material goods, the two logics would merge.

\section{Discussion}

Our proposal distinguishes the sphere of the abundant Commons, and the sphere of cooperatives and ethical companies which deal with the allocation of scarce resources. The two spheres converge in the workers who are both contributors to the Commons and realize their livelihood in the co-operative sphere. Of course, there is no doubt that the capitalist power can severely impede the co-operative economy. As a result the co-ops may often exaggerate their adaptation to the capitalist system. This is precisely why we propose the concept of open co-operativism, which can be seen as a new form where the link to the Commons and the common good is constitutionally obligatory.

Furthermore, capital understands the hypercompetitive and hyperproductive nature of peer production, and invests in it. That is why we believe that the ethical Commons-oriented coalitions, which would produce, protect and use their Commons through reciprocity licenses, could gain an extraordinary competitive edge. While the GPL licenses effectively enable a social logic of unlimited use, this includes use by multinational companies. The PPL restricts it. Of course we do not take the PPL as perfect, but as a new kind of Commons-based reciprocity licenses, whose detailed modalities can very well differ from the original PPL. Such licenses would fully allow commercial exploitation, but ask for reciprocity.

Take for example a traditional indigenous community using a GPL or a similar license. This means any commercial entity could use the knowledge and commercialize it, without any benefit or profit-sharing with the creators of the knowledge. A Commons-based reciprocity license would simply ask for reciprocity and would allow these traditional communities to generate autonomous living and livelihoods, something which is harder to do with the GPL. Furthermore, a Commons-based reciprocity license would not prohibit commercial exploitation but actually encourage it, while the non-commercial licenses prohibit it. The latter do not undermine sharing, but commercialization. While the PPL/Commonsbased reciprocity licenses would encourage and allow both sharing and commercialization.

In fact, there is only self-determination of the contributory process in the GPL context, but full alienation to the capital in the surrounding commercial sphere. By contrast, the PPL not only allows full self-determination in the contributory sphere, but also requires selfmanagement in the co-operative sphere of self-reproduction. This is much more difficult with the GPL, since it subsumes livelihoods to capital accumulation. Moreover, the GPL does not demand nor create direct reciprocity between people. It is entirely possible to use GPL material without any reciprocity, as the overwhelming majority of its users actually do. But the GPL requires what anthropologists call "general reciprocity", that is at the collective level, a minimum of contributions is needed to sustain the system. Nevertheless there is absolutely no requirement for direct reciprocity. The reciprocity is between the individual and the system as a whole. A coder or Wikipedia contributor cannot expect any return from any particular individual but only expects the benefits of the whole system, which depend only on a general flow of contributions.

On the other hand, the PPL/Commons-based reciprocity licenses would indeed limit the non-reciprocity for for-profit entities, however they would not demand equivalent exchange, but only some form of negotiated reciprocity. The important aspect is to generate a flow of 
realized value, necessary for social reproduction, from the sphere of capital accumulation to the sphere of the Commons. The second aspect is organizational. The PPL arguably promotes the self-organization of an ethical economy, and makes those who want to join it, conscious of that fact (including for-profit companies which can decide to ally with the ethical entrepreneurial coalition).

It is important to highlight that the Commons-based reciprocal licenses, like PPL, are not merely about redistribution of value, but about changing the mode of production. Our approach is to transform really existing peer production, which is today not a full mode of production being incapable of assuring its own self-reproduction. This is exactly why the convergence of peer production in the sphere of abundance must be linked to the sphere of co-operative production, and thus insure its self-reproduction. Like in any past phase transition, the existence of a proto-counter-economy, and the resources that this allocates to the counter-hegemonic forces, are absolutely essential for a political and social change. This was arguably the weakness of classic socialism, that is, it had no alternative mode of production, and could only institute state control after a takeover of power.

In other words it is difficult, if not impossible, to wait and see the organic and emergent development of peer production into a fully alternative system. If we follow such an approach, peer production would just remain a parasitic modality dependent on the self-reproduction through capital. We argue that the expectation that one can change the society, by merely producing open code and design, while remaining subservient to capital, is a dangerous pipe dream. By contrast, through the ethical economy surrounding the Commons, it becomes possible to create non-commodified production and exchange.

We thus envision a resource-based economy which would utilize the stigmergic mutual coordination through the gradual application of open book accounting and open supply changes. We deem that there will be no qualitative phase transition merely through emergence, but it will require the reconstitution of powerful political and social movements which aim to become a democratic polis. And that democratic polis, could indeed, through democratic decisions, accelerate the transition. It could take measures that force private economic forces to include externalities, thereby ending infinite capital accumulation.

\section{Conclusion}

The key argument of this article was the following: the current fully-sharing open licenses which allow unrestricted commercial exploitation create a communism of capital, that is a sphere of open knowledge, code and design, which is subsumed to the present dominant political economy. But what we need is an autonomous sphere of peer production, in which commoners and peer producers can create their own livelihood, while staying in the sphere of the Commons. In other words, we need capital for the Commons realizing through a new type of licensing. We are in favour of the PPL, not in its full detail, but as a first of a kind of a Commons-based reciprocal license that encourages commercialization, but transforms it into an ethical economy. In that way it becomes possible to converge the sphere of immaterial Commons contributions with a sphere of co-operative accumulation, through which the surplus value can stay within the sphere of Commons/co-operative production.

\section{References}

Bauwens, Michel. 2013. Thesis on Digital Labor in an Emerging P2P Economy. In Digital Labor. The Internet as Playground and Factory, edited by Trebor Scholz, 207-210. New York: Routledge.

Coleman, Gabriella. 2004. The Political Agnosticism of Free and Open Source Software and the Inadvertent Politics of Contrast. Anthropological Quarterly 77 (3): 507-519.

Coleman, Gabriella and Alex Golub. 2008. Hacker practice: Moral genres and the cultural articulation of liberalism. Anthropological Theory 8 (3): 255-277.

Coleman, Biella and Mako Hill. 2004. How Free Became Open and Everything Else Under the Sun. M/C Journal: A Journal of Media and Culture, 7. Accessed April 1, 2014. http://journal.mediaculture.org.au/0406/02 Coleman-Hill.php

Kostakis, Vasilis and Michel Bauwens. 2014. Network Society and Future Scenarios for a Collaborative Economy. London: Palgrave Macmillan (forthcoming). 
Kostakis, Vasilis and Stelios Stavroulakis. 2013. The Parody of the Commons. tripleC Communication, Capitalism \& Critique: Journal for a Global Sustainable Information Society 11 (2): 412-424.

Kostakis, Vasilis and Wolfgang Drechsler. 2013. Commons-based Peer Production and Artistic Expression: Two Cases from Greece. New Media \& Society. Accessed April 1, 2014. http://nms.sagepub.com/content/early/2013/11/14/1461444813511929.abstract

Kleiner, Dmytri. 2010. The Telekommunist Manifesto. Amsterdam: Institute of Network Cultures.

Primavera De Filippi and Said Vieira. 2013. The Commodification of Information Commons. In Proceedings of the 1st Global Thematic IASC Conference on the Knowledge Commons, Building Institutions for Sustainable Scientific, Cultural and Genetic Resources Commons, Université Catholique de Louvain, Louvain-la-Neuve, Belgium. Accessed April 1, 2014. http://biogov.uclouvain.be/iasc/doc/full\%20papers/De\%20Filippi\%20-\%20Said\%20Vieira.pdf

Restakis, John. 2010. Humanizing the Economy: Co-operatives in the Age of Capital. Gabriola Island, Canada: New Society Publishers.

\section{About the Authors}

Michel Bauwens

Michel Bauwens is the founder of the Foundation for Peer to Peer Alternatives (P2P Foundation). Among others, he is one of three co-founders and partners of the Commons Strategies Group and, in 2014, he functioned as the research director of the FLOK Society transition program in Ecuador.

Vasilis Kostakis

Vasilis Kostakis (PhD, MSc, MA) is a political economist and founder of the P2P Lab. He is a research fellow at the Tallinn University of Technology as well as a collaborator of the P2P Foundation. 